09

\title{
Прогнозирование радиационно-наведенного поглощения света в волоконных световодах с сердцевиной из нелегированного кварцевого стекла в космических применениях
}

\author{
(C) П.Ф. Кашайкин, ${ }^{1}$ А.Л. Томашук, ${ }^{1}$ М.Ю. Салганский, ${ }^{2}$ И.С. Азанова, ${ }^{3}$ М.К. Цибиногина, ${ }^{3}$ \\ T.В. Димакова, ${ }^{3}$ А.Н. Гурьянов, ${ }^{2}$ E.М. Дианов ${ }^{1}$ \\ ${ }^{1}$ Научный центр волоконной оптики РАН, \\ 119333 Москва, Росссия \\ ${ }^{2}$ Институт химии высокочистых веществ им. Г.Г. Девятых РАН, \\ 603950 Нижний Новгород, Россия \\ ${ }^{3}$ ОАО „Пермская научно-производственная приборостроительная компания“, \\ 614990 Пермь, Россия \\ e-mail: kpf@fo.gpi.ru
}

Поступило в Редакцию 26 марта 2018 г.

В окончательной редакции 19 ноября 2018 г.

Принято к публикации 5 декабря 2018 г.

\begin{abstract}
Исследовано радиационно-наведенное поглощение (РНП) света в пяти изотропных волоконных световодах $(\mathrm{BC})$ с сердцевиной из нелегированного кварцевого стекла $\left(\mathrm{SiO}_{2}\right)$ и фторсиликатной оболочкой и одном двулучепреломляющем ВС типа „ПАНДА“ того же химического состава на длине волны $\lambda=1.55 \mu \mathrm{m}$ при $\gamma$-облучении до дозы $1 \mathrm{kGy}(\sim 1 \mathrm{~Gy} / \mathrm{s})$ и после завершения облучения в течение $15-45 \mathrm{~min}$ и через несколько месяцев при температурах +25 и $-60^{\circ} \mathrm{C}$. Для оценки РНП в конце 15 -летней миссии в космосе сделана экстраполяция РНП после облучения в рамках модели кинетики n-го порядка, которая дала прогноз РНП для изотропных ВС $\sim 1.1$ и $\sim 0.3 \pm 0.1 \mathrm{~dB} / \mathrm{km}$ при -60 и $+25^{\circ} \mathrm{C}$ соответственно. Сделан вывод о возможности использования по меньшей мере $4-5 \mathrm{~km}$ ВС в космосе в условиях вариации температуры в пределах $\pm 60^{\circ} \mathrm{C}$ при максимальной дозе $1 \mathrm{kGy}$ и длительности миссии 15 лет. Также установлено, что РНП к концу такой миссии в двулучепреломляющем ВС будет не выше, чем в изотропных.
\end{abstract}

DOI: 10.21883/JTF.2019.05.47480.123-18

Волоконные световоды (BC) востребованы для применений в космическом пространстве на спутниках в бортовых системах оптической передачи данных и в волоконно-оптических датчиках, в том числе волоконнооптических гироскопах (ВОГ).

ВС на спутниках подвергаются действию космической радиации, создающей в сетке кварцевого стекла микроскопические дефекты (радиационные центры окраски, РЦО), поглощающие световой сигнал, распространяющийся по ВС, т. е. в ВС возникает радиационно-наведенное оптическое поглощение (РНП), которое может сильно ухудшить параметры волоконно-оптической системы вплоть до полной утраты прозрачности ВС. Проблема РНП в космосе усугубляется тем, что ВС будут работать в условиях вариации температуры, а при ее снижении замедляется термический распад РЦО и, как следствие, возрастает РНП.

В бортовых системах оптической передачи данных проблема РНП стоит не столь остро из-за малой длины ВС. С учетом фактора малости длины в Лаборатории военно-морского флота США (Naval Research Laboratory) была сделана оценка для предельно допустимой величины РНП в такой системе на спутнике $300 \mathrm{~dB} / \mathrm{km}[1,2]$. При таком допуске на РНП разработка специальных радиационно-стойких ВС для многих миссий может и не потребоваться. К примеру, на основной современной длине волны для оптической связи $\lambda=1.55 \mu \mathrm{m}$ в стандартном BC SMF-28, содержащем в кварцевом стекле сердцевины примесь германия в концентрации $3.5 \mathrm{~mol} \% \mathrm{GeO}_{2}$, РНП к концу миссии продолжительностью 15 лет с полной поглощенной дозой $1 \mathrm{kGy}$ не превысит $5 \mathrm{~dB} / \mathrm{km}$, а во многомодовом градиентном ВС с германосиликатной сердцевиной и числовой апертурой 0.2 не превысит $20 \mathrm{~dB} / \mathrm{km}$. Эти оценки сделаны в предположении комнатной температуры на протяжении всей миссии. Если вся миссия будет проходить при $-60^{\circ} \mathrm{C}$, то РНП в SMF-28 не должно превысить $75 \mathrm{~dB} / \mathrm{km}$, а во многомодовом ВС - $40 \mathrm{~dB} / \mathrm{km}$. Таким образом, при таких условиях проблемы с РНП в бортовых системах оптической передачи данных быть не должно.

Однако при более жестких условиях миссии (бо́ льшая доза, ниже температура, рабочий спектральный диапазон включает и более короткие длины волн) ВС, содержащие германий, могут проявить недопустимо большое РНП. Решением для таких миссий будет использование одномодовых ВС с сердцевиной из нелегированного кварцевого стекла $\left(\mathrm{SiO}_{2}\right)$ и многомодовых градиентных $\mathrm{BC}$ со фтором в сердцевине из $\mathrm{SiO}_{2}$ [3]. Для изготовления таких многомодовых ВС требуется плазмохимическая технология PCVD [4].

Актуальной задачей является достижение низкого РНП в одномодовых двулучепреломляющих ВС в ВОГ. Длина такого ВС составляет $1-5 \mathrm{~km}$, а предельно до- 
пустимое РНП не превышает единиц $\mathrm{dB} / \mathrm{km}$ (рабочая длина волны $\lambda=1.55 \mu \mathrm{m})$. Наиболее подходящими являются одномодовые двулучепреломляющие ВС с сердцевиной из нелегированного $\mathrm{SiO}_{2}$ и фторсиликатной светоотражающей оболочкой $[5,6]$.

Ранее установлено, что РЦО в ВС с сердцевиной из нелегированного $\mathrm{SiO}_{2}$ при космических дозах $(<10 \mathrm{~Gy})$ могут быть обусловлены двумя факторами: деформациями сетки стекла ВС и наличием в ней примеси хлора [7-10]. Хлорный РЦО имеет максимум РНП в ультрафиолетовой области, а деформационные РЦО в видимой области, при этом хвосты и тех и других РЦО и создают значительное РНП и на $\lambda=1.55 \mu \mathrm{m}$.

Недавно была продемонстрирована возможность оптимизации технологических режимов получения преформ изотропных ВС с сердцевиной из нелегированного $\mathrm{SiO}_{2}$ и фторсиликатной оболочкой с целью снижения РНП в высокоинтенсивных полях ионизирующего излучения (мощность дозы $\sim 1 \mathrm{~Gy} / \mathrm{s}$ и более) [7,8,11]. $\mathrm{B}$ частности, путем создания большого избытка $\mathrm{O}_{2}$ над $\mathrm{SiCl}_{4}$ в парогазовой смеси в процессе синтеза стекла сердцевины преформы ВС удалось предотвратить вхождение хлора в сетку стекла и тем самым практически полностью исключить увеличение РНП за счет хлорных РЦО. Кроме того, за счет точного согласования отношения молярных расходов $\mathrm{O}_{2}$ и $\mathrm{SiCl}_{4}$ с концентрацией фтора в оболочке удалось добиться существенного снижения деформаций сетки стекла, возникающих при вытяжке ВС, и тем самым существенно подавить РЦО, вызванные деформациями сетки $[7,8]$. Таким образом, в результате оптимизации технологических режимов получения преформ удалось снизить РНП в ближнем ИК-диапазоне, более чем на порядок [8].

Возникает вопрос, в какой мере такая оптимизация технологии способна уменьшить РНП в космосе, когда мощность дозы несоизмеримо меньше $\left(10^{-6}-10^{-5} \mathrm{~Gy} / \mathrm{s}\right)$, но при этом возможно снижение температуры.

В лабораторных условиях проблематично создать сценарий эксперимента, полностью аналогичный космическому облучению (доза $\sim 1 \mathrm{kGy}$ поглощается световодом за время работы на орбите $10-15$ лет $[1,2] !)$. Поэтому, необходимо применять методы ускоренного тестирования. Наиболее распространенный в мире метод основывается на так называемой модели кинетики $n$-го порядка $[1,12-15]$. Суть применения данной модели к оценке РНП в космосе заключается в следующем. ВС облучают в лабораторных условиях до дозы, которую ВС должен получить к концу миссии, при этом мощность дозы может быть гораздо больше космической (на порядки величины). Затем после завершения облучения измеряется зависимость спада РНП от времени и по уравнениям модели делается экстраполяция РНП на момент времени, равный полной продолжительности миссии $[1,12-15]$.

Экспериментальная проверка модели кинетики $n$-го порядка была успешно осуществлена в работе [14]: экстраполяционные значения РНП на момент времени 9.5 лет, полученные из экспериментов с мощностями дозы, отличающимися в 50 (!) раз, отлично совпали между собой.

Цели настоящей работы: 1) сравнение РНП в изотропных одномодовых ВС с сердцевиной из нелегированного $\mathrm{SiO}_{2}$, изготовленных в различных технологических режимах, в том числе оптимизированных для снижения РНП в задачах атомной энергетики при больших мощностях дозы; 2) сравнение РНП в изотропных и двулучепреломляющих ВС с сердцевиной из нелегированного и легированного германием $\left.\mathrm{SiO}_{2} ; 3\right)$ экстраполяция $\mathrm{PHП}$ на время космической миссии 15 лет.

В настоящей работе мы постулировали дозу, поглощенную к концу миссии $(1 \mathrm{kGy})$, при вариации температуры в пределах $\pm 60^{\circ} \mathrm{C}$, что хорошо соответствует среднему значению дозы при длительности космической миссии продолжительностью $10-15$ лет $[1,2,14]$.

\section{1. Детали эксперимента}

\section{Образиы}

Методом MCVD в ИХВВ РАН были изготовлены пять преформ ВС $1-5$ (табл. 1) с сердцевиной из нелегированного $\mathrm{SiO}_{2}$ и фторсиликатной светоотражающей оболочкой. В НЦВО РАН из этих преформ были вытянуты изотропные одномодовые ВС при одинаковых условиях вытяжки. ВС 1,3 и 4 были ранее исследованы при более высоких дозах при комнатной температуре в работе [7], а ВС 1, 2 и 5 - в работе [8].

Преформы ВС $1-5$ были синтезированы в различных технологических режимах. Во-первых, ВС 2 и 5 имели более низкое содержание фтора в оболочке, что привело к более низкой разности показателей преломления сердцевины и оболочки $(\Delta n=0.005)$, в то время как у остальных ВС $\Delta n=0.009-0.0095$.

Во-вторых, отношение $r$ молярных расходов $\mathrm{O}_{2}$ и $\mathrm{SiCl}_{4}$ на стадии синтеза сердцевины варьировало между преформами (в табл. $1 r$ нормировано на $r_{0}=29$ ). Эти два технологических фактора $(\Delta n$ и $r)$ и их взаимосоответствие практически полностью определили РНП в ближнем ИК-диапазоне, как было установлено в предыдущих работах $[7,8]$.

С увеличением значения $r$ содержание хлора в сердцевине уменьшалось, как следует из прямых измерений концентрации, проведенных в [7] (табл. 1). Поэтому $\mathrm{BC} 1$ и 5, изготовленные с наибольшим значением $r=2-2.2$, вообще не проявили хлорных РЦО в предыдущих работах $[7,8]$.

ВС 4 с $r=1$ продемонстрировал хлорные РЦО, но только в процессе релаксации после завершения облучения, тогда как РНП во время облучения было в основном обусловлено деформационными РЦО [7].

РНП у ВС 3 с наименьшим значением $r$, напротив, было в основном обусловлено хлорными РЦО, однако, быстрый спад РНП в течение 1 min релаксации после 
Таблица 1. Характеристики световодов

\begin{tabular}{|c|c|c|c|c|c|c|}
\hline Обозначение ВС & $\begin{array}{c}\Delta n \\
\left(10^{-3}\right)\end{array}$ & $r$ & $\begin{array}{c}\text { Концентрация } \\
\mathrm{GeO}_{2} \text { в сердцевине } \\
\text { (mol.\%) }\end{array}$ & $\begin{array}{c}\text { Концентрация } \\
\mathrm{Cl} \text { в сердцевине } \\
\text { (wt.ppm) }\end{array}$ & $\begin{array}{c}\text { Степень } \\
\text { вмороженных } \\
\text { деформаций } \\
\text { сетки стекла }\end{array}$ & $\begin{array}{c}\text { Обозначения ВС } \\
\text { в предыдущих работах }\end{array}$ \\
\hline 1 & 9.5 & 2 & - & 86 & низкая & $\begin{array}{c}{[7],{ }_{,} \mathrm{O}_{2}: \mathrm{SiO}_{2}{ }^{“}} \\
{[8],{ }_{\text {,fiber }} 5^{\circ}}\end{array}$ \\
\hline 2 & 5.0 & 1 & - & - & низкая & {$[8]$, ,fiber $8^{\varsigma}$} \\
\hline 3 & 9.5 & 0.4 & - & 230 & средняя & [7], $,{ }_{,} \mathrm{Cl}: \mathrm{SiO}_{2}{ }^{6}$ \\
\hline 4 & 9.0 & 1 & - & 192 & высокая & {$[7],,{ }_{,} \mathrm{SiO}_{2}-\mathrm{II}^{\prime \prime}$} \\
\hline 5 & 5.0 & 2.2 & - & - & высокая & {$[8]$, ,fiber $2^{\prime \prime}$} \\
\hline PANDA-SiO ${ }_{2}$ & $\sim 10$ & - & - & - & - & - \\
\hline SMF-28 & 5.0 & - & 3.5 & - & - & - \\
\hline PANDA-GeO ${ }_{2}$ & $\sim 10$ & - & 7 & - & - & - \\
\hline
\end{tabular}

Примечание. $\Delta n-$ разность показателей преломления сердцевины и оболочки, $r-$ отношение молярных расходов $\mathrm{O}_{2}$ и $\mathrm{SiCl}_{4}$ при осаждении сердцевины преформы, нормированное на $r_{0}=29$.

прекращения облучения (на $\sim 20 \%$ ) в предыдущем исследовании [7] указал на некоторый вклад и деформационных РЦО, отличающихся малым временем жизни.

В ВС 1 и 2 значение $r$ было сбалансировано с содержанием $\mathrm{F}$ в оболочке, поэтому деформации сетки стекла и вызванные ими РЦО были в этих ВС минимальны. РНП в ВС 1 и 2 во время и после облучения при мощности дозы $8.7 \mathrm{~Gy} / \mathrm{s}$ до $94 \mathrm{kGy}$ практически совпали на длине волны $\lambda=1.31 \mu \mathrm{m}$ и лишь незначительно отличались на $\lambda=1.55 \mu \mathrm{m}$ из-за, по-видимому, чуть большего содержания хлора в ВС 2. Это, в свою очередь, было вызвано в два раза меньшим избытком кислорода при синтезе сердцевины преформы ВС 2 [8] (табл. 1).

ВС 4 и 5 имели сильное несоответствие между значением $r$ и содержанием фтора в оболочке (табл. 1) и поэтому значительные вмороженные деформации, бб́льшие, чем у ВС $1-3$. По этой причине и РНП в ВС 4 и 5 в предыдущем исследовании при мощности дозы $8.7 \mathrm{~Gy} / \mathrm{s}$ было наибольшим [8].

Таким образом, предыдущие исследования [7,8] выявили существенное различие РНП у ВС $1-5$. Возникал вопрос, как проявятся эти различия при моделировании РНП в космических условиях и какой ВС окажется лучшим.

Кроме изотропных ВС $1-5$ в ОАО „Пермская научнопроизводственная приборостроительная компания“ были изготовлены два одномодовых двулучепреломляющих ВС типа „ПАНДА“ с сердцевиной из нелегированного $\mathrm{SiO}_{2}$ („PANDA-SiO ${ }_{2}$ “) и кварцевого стекла, легированного германием („PANDA-GeO ${ }_{2}{ }^{6}$ ).

Также для сравнения исследовался стандартный одномодовый ВС для оптической связи SMF-28.

\section{Эксперимент}

Гамма-облучение ВС проводилось в НИЦ „Курчатовский институт“ на установке ГУТ-200М с активным источником ${ }^{60} \mathrm{Co}$.

Отрезки световодов длиной 30-200 m были намотаны на катушки диаметром $80 \mathrm{~mm}$. Катушки облучались поочередно, для чего они размещались в термостате, который, в свою очередь, располагался в одной и той же калиброванной по мощности дозы точке в облучательной камере. Концы исследуемых ВС были приварены к специальным радиационно-стойким ВС, подсоединенным к источнику света и спектрометру, находящимся за биологической защитой.

После подъема кобальтовых стержней из подземного хранилища ВС подвергались воздействию $\gamma$-излучения с мощностью дозы $1.0-1.1 \mathrm{~Gy} / \mathrm{s}$ при температуре -60 или $+25^{\circ} \mathrm{C}$. Облучение продолжалось в течение $15-16 \mathrm{~min}$ до общей поглощенной дозы $\sim 1 \mathrm{kGy}$. После прекращения облучения происходила релаксация РНП в световодах в течение 15-45 min, а температура оставалась постоянной при облучении и релаксации с точностью $\pm 1.5^{\circ} \mathrm{C}$.

В процессе облучения и релаксации с временным шагом $30 \mathrm{~s}$ происходила регистрация спектров в ближнем ИК-диапазоне с помощью спектрометра на диодной линейке состава InGaAs NIR-128 фирмы „Avantes“ (регистрируемый спектральный диапазон 1100-1700 nm), или NIRQuest 512 фирмы „Ocean Optics“ (900-1750 nm). Источником света служила галогеновая лампа накаливания HL-2000 фирмы „Avantes“. Для минимизации эффекта фотообесцвечивания РЦО видимая часть спектра $(\lambda<900 \mathrm{~nm})$ на входе в ВС обрезалась с помощью фильтра ИКС-3. Мощность зондирующего света в ВС в этом случае не превышала $0.5 \mu \mathrm{W}$.

Подробная схема экспериментальной установки представлена в работе [16].

После облучения на установке ГУТ-200М ВС были возвращены в НЦВО РАН, где в течение некоторого времени (от 1 до 22 месяцев) в них проводились измерения РНП на длине волны $1.55 \mu \mathrm{m}$ с помощью оптического рефлектометра EXFO FTB-400. Эти дополнительные точки зависимости РНП от времени позволили повысить точность экстраполяции РНП на момент времени „15 лет“. 


\section{2. Результаты и обсуждение}

На рис. 1, 2 представлены результаты $\gamma$-облучения $\mathrm{BC}$ при $T=-60^{\circ} \mathrm{C}$ : на рис. 1 показана эволюция РНП в процессе облучения и релаксации на длине волны $\lambda=1.55 \mu \mathrm{m}$, на рис. 2, $a$ представлены спектры РНП, измеренные во время облучения при поглощенной дозе $1 \mathrm{kGy}$, на рис. $2, b-$ спектры РНП, измеренные через 15 min релаксации после завершения облучения до дозы $1 \mathrm{kGy}$.

Из рис. 1 видно, что ВС 1-3 демонстрируют практически одинаковое РНП на длине волны $\lambda=1.55 \mu \mathrm{m}$ в процессе облучения во всем диапазоне доз до $1 \mathrm{kGy}$ (за исключением только небольшого выброса РНП в начале облучения в ВС 2 и 3 , физическая природа которого объяснена в [16] и который никак не повлиял на эволюцию РНП при дозах более $~ 100 \mathrm{~Gy})$. Стоит обратить внимание на то, что РНП в неоптимизированных ВС 4 и 5 , содержащих значительные деформации сетки стекла, в 3-4 раза больше. В этих ВС также проявился небольшой скачок РНП в начале облучения.

Несмотря на разницу РНП непосредственно в процессе облучения, через $30 \mathrm{~min}$ релаксации после облучения все ВC с нелегированной сердцевиной показали очень близкое значение РНП на длине волны $\lambda=1.55 \mu \mathrm{m}-$ $5.2 \pm 1.0 \mathrm{~dB} / \mathrm{km}$. Напомним, что для космических применений важно именно РНП при релаксации. Из рис. 1 также видно, что РНП в ВС с германием в сердцевине практически не релаксирует при $T=-60^{\circ} \mathrm{C}$.

Сравнение спектров РНП, измеренных в процессе облучения при $T=-60^{\circ} \mathrm{C}$ (рис. 2, $a$ ), показывает, что именно коротковолновый хвост РНП вносит основной вклад в общее РНП на длине волны $\lambda=1.55 \mu \mathrm{m}$ во всех исследованных ВС. Из ВС с сердцевиной из нелегированного $\mathrm{SiO}_{2}$ этот хвост наиболее интенсивен в

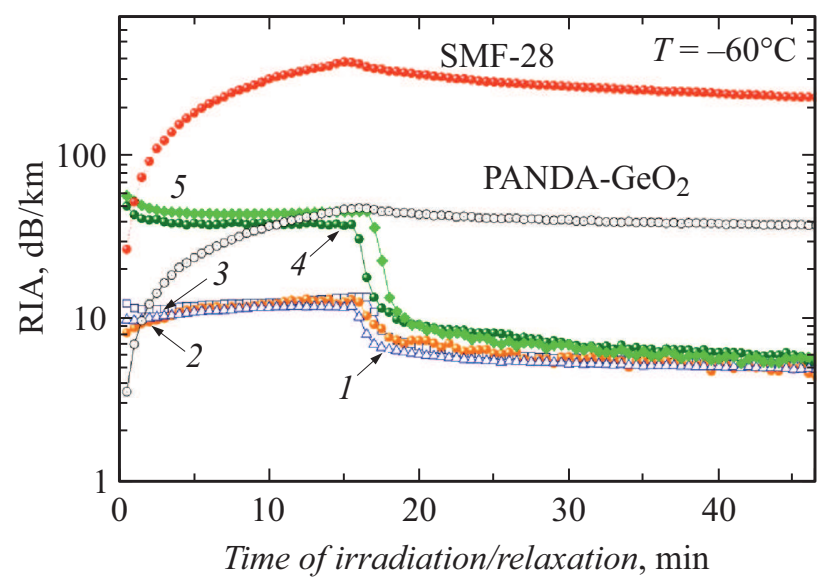

Рис. 1. Эволюция РНП (RIA) в ВC $1-5$ с сердцевиной из нелегированного $\mathrm{SiO}_{2}$ и в двух германосиликатных световодах SMF-28 и PANDA-GeO ${ }_{2}$ в процессе $\gamma$-облучения на длине волны $\lambda=1.55 \mu \mathrm{m}$ до дозы $\sim 1 \mathrm{~Gy}$ при мощности дозы 1.0 или $1.1 \mathrm{~Gy} / \mathrm{s}$ (в течение 16 или $15 \mathrm{~min}$ соответственно) и в течение $\sim 30 \mathrm{~min}$ релаксации после облучения. Облучение ВС и измерение РНП поведено при $T=-60^{\circ} \mathrm{C}$.
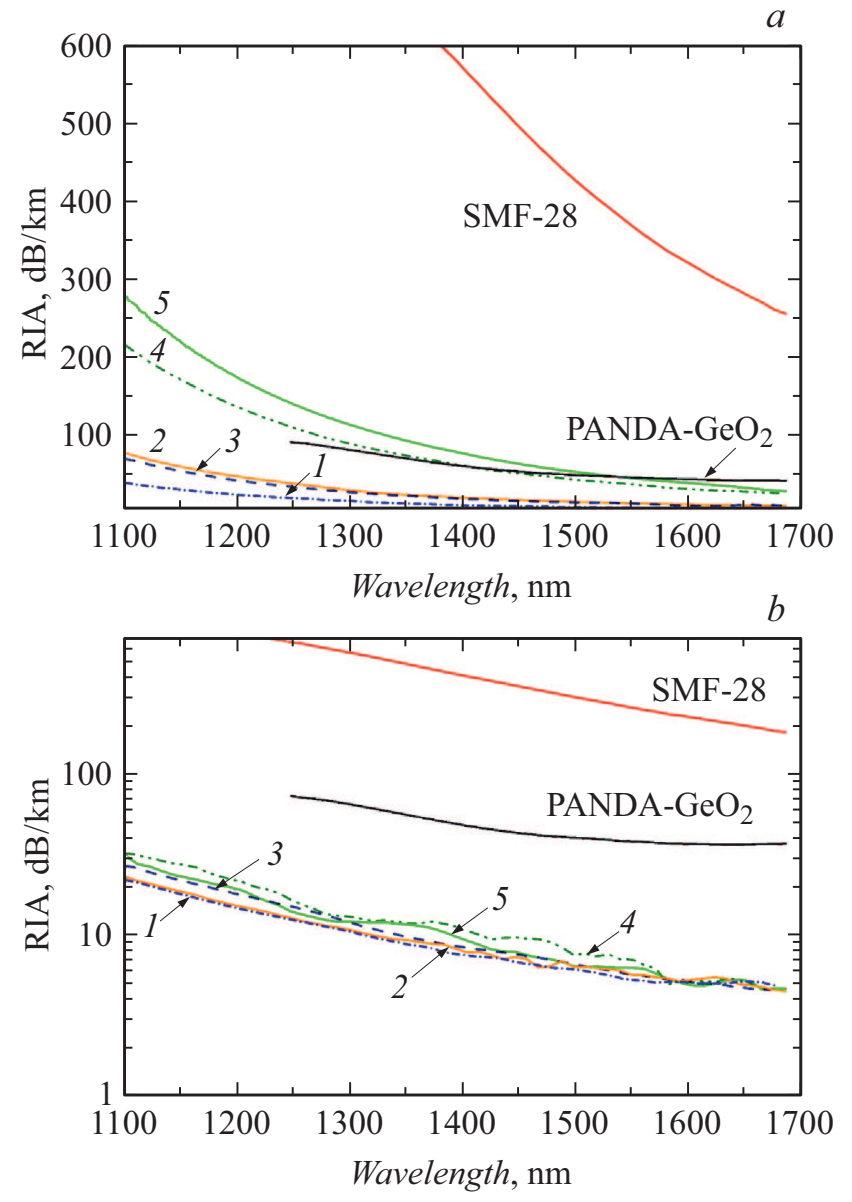

Рис. 2. Спектры РНП (RIA) в ВC $1-5$ с сердцевиной из нелегированного $\mathrm{SiO}_{2}$ и в двух германосиликатных световодах SMF-28 и PANDA-GeO 2 в процессе облучения при поглощенной дозе $\sim 1 \mathrm{kGy}(a)$ и через $15 \mathrm{~min}$ релаксации после завершения облучения до дозы $1 \mathrm{kGy}(b)$. Облучение ВC и измерение спектров проведено при $T=-60^{\circ} \mathrm{C}$.

ВС 4 и 5 с наиболее деформированной сеткой стекла. Наименьший коротковолновый хвост демонстрирует ВС 1, имеющий наименьшие деформации сетки стекла и содержащий лишь малую примесь хлора в сердцевине. В случае световодов ВС 2 и 3 коротковолновый хвост, очевидно, связан с хлорными РЦО.

Интересным является тот факт, что световод SMF-28, имеющий в два раза меньшее содержание $\mathrm{GeO}_{2}$ в сердцевине, чем световод PANDA-GeO ${ }_{2}$, продемонстрировал тем не менее гораздо большее РНП во всем исследуемом спектральном диапазоне. Меньшее РНП в $\mathrm{BC}$ с бо́льшей концентрацией $\mathrm{GeO}_{2}$ в сердцевине наблюдается только при пониженных температурах, тогда как при комнатной температуре зависимость РНП от концентрации $\mathrm{GeO}_{2}$ обратная. Этот эффект заслуживает отдельного исследования.

Спектры РНП всех ВС с сердцевиной из нелегированного $\mathrm{SiO}_{2}$ через $15 \mathrm{~min}$ релаксации (рис. $2, b$ ) практически совпали, что коррелирует с результатом на рис. 1. Видно, что, как и в процессе облучения (рис. 2, a), 
Таблица 2. Коэффициенты экстраполяции и прогнозируемые значения РНП через 15 лет миссии

\begin{tabular}{|c|c|c|c|c|c|c|}
\hline $\mathrm{BC}$ & $\begin{array}{c}\text { Темпе- } \\
\text { ратура, } \\
{ }^{\circ} \mathrm{C}\end{array}$ & $\begin{array}{c}A_{0} \\
\mathrm{~dB} / \mathrm{km}\end{array}$ & $\begin{array}{c}A_{f} \\
\mathrm{~dB} / \mathrm{km}\end{array}$ & $\begin{array}{c}\tau, \\
\min \end{array}$ & $n$ & $\begin{array}{c}\text { РНП через } \\
15 \text { лет } \\
\text { dB/km }\end{array}$ \\
\hline SMF-28 & \multirow{3}{*}{+25} & 25.2 & 3.8 & 36.6 & 5.2 & 4.3 \\
\hline PANDA-GeO ${ }_{2}$ & & 28.9 & 17.0 & 220.6 & 6.1 & 17.5 \\
\hline 1 & & 9.2 & 0.0 & 0.1 & 9.6 & 0.27 \\
\hline 1 & -60 & 16.0 & 0.0 & 0.8 & 9.2 & 1.1 \\
\hline
\end{tabular}

максимумы всех РЦО лежат в коротковолновой области спектра.

Экстраполяция релаксации РНП на длине волны $\lambda=1.55 \mu \mathrm{m}$ на время миссии в космосе в 15 лет проводилась в рамках модели кинетики $n$-го порядка $[1,12-15]$ (рис. 3) по формуле

$$
\begin{gathered}
A(t)=\left(A_{0}+A_{f}\right)(1+c t)^{-x}+A_{f}, \\
c=\left(2^{n-1}-1\right) / \tau, \quad x=1 /(n-1),
\end{gathered}
$$

где $A(t)$ - зависимость РНП от времени после облучения, $A_{0}$ - исходное РНП в начале релаксации, $A_{f}-$ РНП в конце экстраполяции; $\tau-$ время, за которое РНП в процессе релаксации уменьшается в 2 раза, $n-$ порядок кинетики релаксации РНП $[1,12-15]$. Все четыре параметра уравнений (1) и (2) $-A_{0}, A_{f}, \tau$ и $n-$ были найдены численно с помощью компьютерного программного обеспечения (табл. 2).

Для трех ВС, облученных также и при комнатной температуре (рис. 3), были измерены дополнительные точки РНП через 40, 155, 173, 270 и 663 дней после облучения с помощью оптического рефлектометра методом OTDR (Optical Time Domain Reflectometry), что позволило повысить точность экстраполяции [12]. Точки РНП, измеренные для световода PANDA- $-\mathrm{GeO}_{2}$ через 270 и 663 дней после окончания облучения, при построении экстраполяции не учитывались, но при этом попали на экстраполяционную кривую с хорошей точностью. Этот факт свидетельствует о высокой точности использованной модели при экстраполяции РНП на срок 15 лет по измерениям РНП только в течение первых $30 \mathrm{~min}$ релаксации, а затем через 40 дней после облучения. Стоит отметить, что экстраполяция для ВС 1 при $T=60^{\circ} \mathrm{C}$ была проведена только на основе $45 \mathrm{~min}$ релаксации и поэтому не является столь же точной, как три другие экстраполяции.

Для двулучепреломляющего BC PANDA- $\mathrm{GeO}_{2}$ экстраполяция РНП на 15 лет даже при комнатной температуре дала $\sim 18 \mathrm{~dB} / \mathrm{km}$, что, очевидно, является недопустимо большим значением (рис. 3, табл. 2). Прогноз для световода SMF-28 при комнатной температуре $(4.3 \mathrm{~dB} / \mathrm{km})$ можно считать удовлетворительным для длины отрезка ВС в космосе $\sim 1-1.5 \mathrm{~km}$, однако, как следует из рис. $2, a$, при $T=-60^{\circ} \mathrm{C}$ РНП в этом $\mathrm{BC}$ будут неприемлемо высоко.

Из рис. 3 видно, что в течение первых $2.5 \mathrm{~min}$ релаксации РНП у ВС 1 при обоих температурах происходил сверхбыстрый распад короткоживущих РЦО, которые, очевидно, не возникли бы при несоизмеримо более низкой мощности дозы в космосе. Поэтому эти точки РНП мы не учитывали при построении релаксации так же, как это делалось и в работах других авторов $[12,14]$.

Интересно, что модель предсказала релаксацию РНП до нуля $\left(A_{f} \sim 0\right)$ для ВС 1 при комнатной температуре и при $T=-60^{\circ} \mathrm{C}$ при времени релаксации, стремящемся к бесконечности. Следует также отметить, что значения $\mathrm{n}$ экстраполяции ВС 1 оказались довольно близкими при обеих температурах $(n=9.2$ и 9.6), что, по всей видимости, закономерно.

Вилка значений РНП $0.27-0.47 \mathrm{~dB} / \mathrm{km}$ в момент времени „173 дня“ на экстраполяционной кривой ВС 1 при $T=25^{\circ} \mathrm{C}$ показывает разброс РНП среди всех пяти ВС с сердцевиной из нелегированного $\mathrm{SiO}_{2}$; при этом РНП у ВС 1 лежит точно по середине этой вилки. Видно, что РНП в ВС 1 составит $\sim 0.27 \mathrm{~dB} / \mathrm{km}$ в конце 15 -летней миссии при комнатной температуре и $\sim 1.1 \mathrm{~dB} / \mathrm{km}$, если вся миссия будет проходить при $T=-60^{\circ} \mathrm{C}$ (рис. 2, табл. 2). Исходя из вилки РНП для ВС $1-5$ в момент времени „173 дня“, можно сделать приблизительную оценку разброса РНП в момент времени „15 лет“ $\sim 0.2-0.4 \mathrm{~dB} / \mathrm{km}$. Таким образом, можно заключить, что при $T=+25^{\circ} \mathrm{C}$ к концу 15 -летней космической миссии все ВС $1-5$ будут иметь достаточно низкий уровень

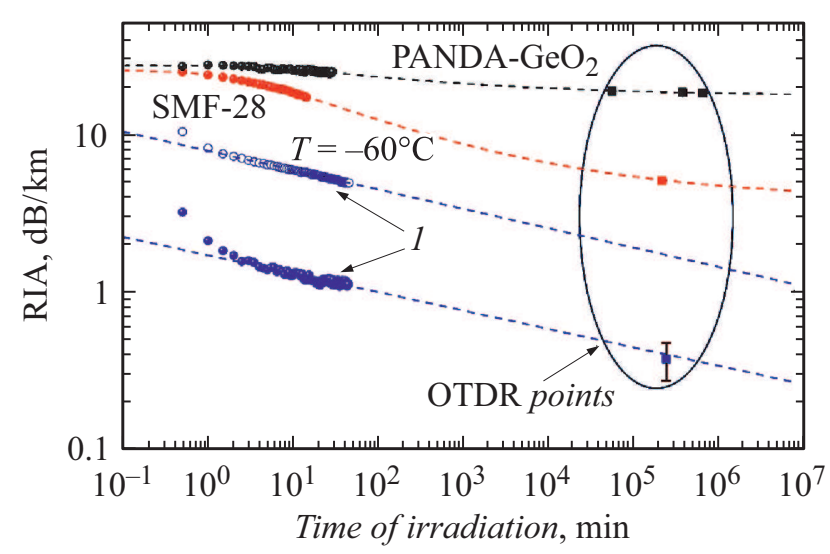

Рис. 3. РНП (RIA) в течение $15-45$ min после завершения $\gamma$-облучения до дозы $1 \mathrm{kG}$ в четырех ВС (круги) и значения РHП, измеренные по методу OTDR через 40, 155, 173, 270 и 663 дней после завершения $\gamma$-облучения (прямоугольники). РНП в одном отрезке ВС 1 измерялось при $T=-60^{\circ} \mathrm{C}$ (открытые круги), а в трех остальных отрезках ВС - при $T=+25^{\circ} \mathrm{C}$. Пунктирные линии показывают экстраполяцию экспериментальных точек РНП на время $10^{7} \mathrm{~min}$ по модели кинетики n-го порядка. Вилка значений РНП у ВС 1, измеренная через 173 дня после облучения, показывает разброс РНП среди всех пяти ВС $1-5$. Начальные точки РНП у ВС 1 на временах менее $2.5 \mathrm{~min}$, соответствующие сверхбыстрой релаксации РНП, при построении экстраполяционных кривых не учитывались. 

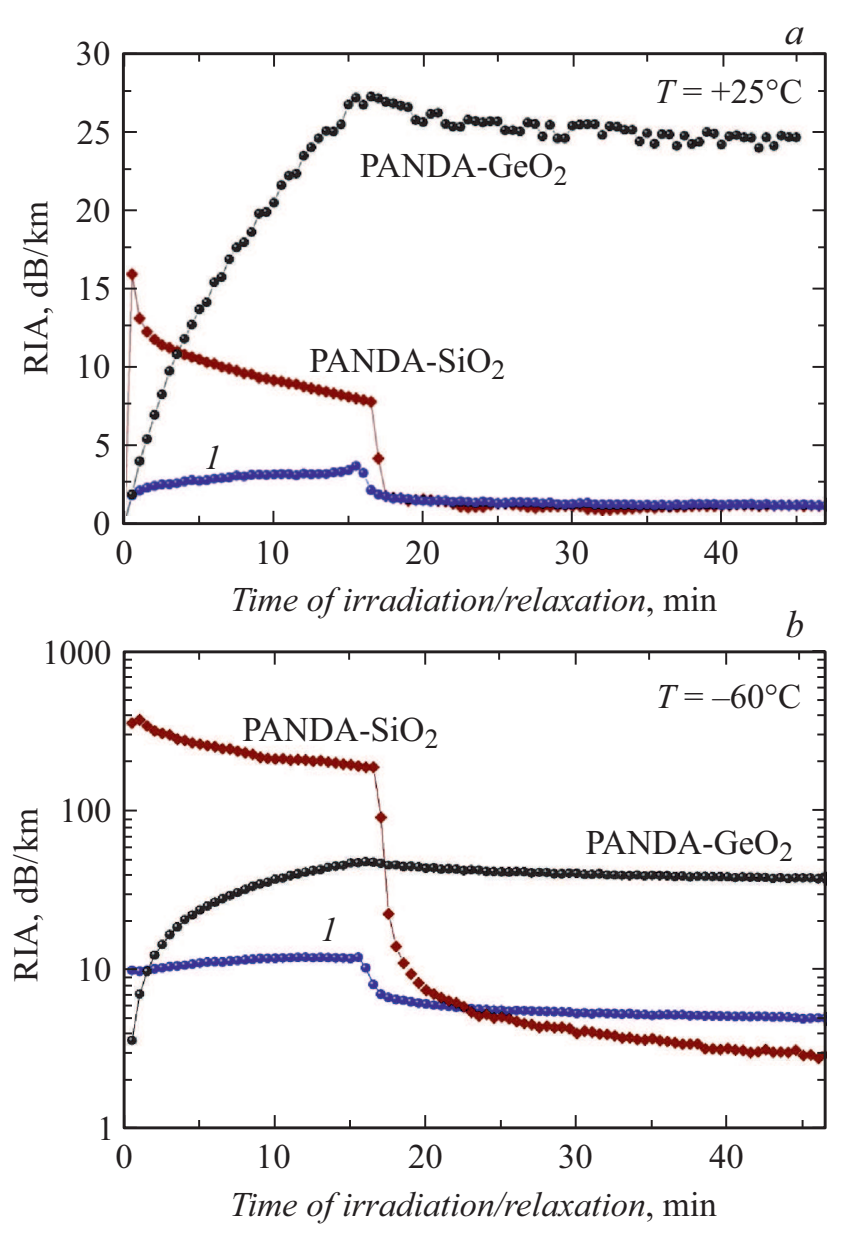

Рис. 4. Эволюция РНП (RIA) в ВC 1 с сердцевиной из нелегированного $\mathrm{SiO}_{2}$ и в двух двулучепреломляющих световодах PANDA- $\mathrm{SiO}_{2}$ и PANDA- $\mathrm{GeO}_{2}$ в процессе $\gamma$-облучения на длине волны $\lambda=1.55 \mu \mathrm{m}$ до дозы $\sim 1$ Gу при мощности дозы 1.0 или $1.1 \mathrm{~Gy} / \mathrm{s}$ (в течение 16 или $15 \mathrm{~min}$ соответственно) и в течение $\sim 30 \mathrm{~min}$ релаксации после облучения. Облучение ВС и измерение РНП поведено при $T=+25^{\circ} \mathrm{C}(a)$ и при $T=-60^{\circ} \mathrm{C}(b)$.

РНП для использования отрезков длиной $10 \mathrm{~km}$ и более. Если же вся миссия будет проходить при $T=-60^{\circ} \mathrm{C}$, то допустимая длина ВС будет, очевидно, меньше и составит 4-5 km. Однако напомним, что сделанная экстраполяция РНП при $T=-60^{\circ} \mathrm{C}$ была, скорее всего, недостаточно точной, так как мы не смогли поддерживать данную температуру ВС в течение длительного времени и поэтому не были проведены измерения РНП спустя месяцы после облучения. Тем не менее можно с достаточной определенностью утверждать, что в условиях вариации температуры в пределах $\pm 60^{\circ} \mathrm{C}$ при максимальной дозе $1 \mathrm{kGy}$ и длительности миссии 15 лет, использование, по меньшей мере, 4-5 km ВС с сердцевиной из нелегированного $\mathrm{SiO}_{2}$ возможно.

Интересным является тот факт, что в отличие от применений ВС с сердцевиной из нелегированного $\mathrm{SiO}_{2}$ при высоких мощностях дозы, когда РНП в зависимости от режимов изготовления преформы может отличаться многократно $[7,8,16]$, при малой космической мощности дозы все ВС с сердцевиной из нелегированного $\mathrm{SiO}_{2}$ проявят приблизительно одинаковое РНП. Поэтому какая-то дополнительная оптимизация технологии преформ ВС с сердцевиной из нелегированного $\mathrm{SiO}_{2}$ для уменьшения РНП в космосе не требуется.

На рис. 4 показаны эволюция РНП в процессе облучения и релаксации $\mathrm{BC}$ PANDA-SiO 2 на $\lambda=1.55 \mu \mathrm{m}$ при $T=+25$ и $-60^{\circ} \mathrm{C}$ соответственно. Для сравнения приведены соответствующие кривые для ВС 1 и PANDA-GeO ${ }_{2}$.

Во-первых, обращает на себя внимание большое РНП в PANDA-SiO 2 непосредственно в процессе облучения, особенно в сравнении с изотропным ВС 1. РНП резко возрастает в начале облучения, а потом плавно снижаются по мере продолжения облучения. Такое поведение характерно для РНП, вызванных деформациями сетки стекла [16]. Очевидно, что причина более значительных деформаций сетки стекла в $\mathrm{PANDA}-\mathrm{SiO}_{2}$, чем в изотропном ВC 1 , состоит в наличии напрягающих боросиликатных стержней, создающих двулучепреломление.

Однако деформационные $\mathrm{PЦO}$ в PANDA-SiO 2 оказались очень короткоживущими: при $T=+25^{\circ} \mathrm{C}$ сразу после завершения облучения РНП падает до уровня РНП в ВС 1 (рис. $4, a$ ), а при $T=-60^{\circ} \mathrm{C}-$ даже ниже уровня РНП, измеренного в ВС 1 (рис. $4, b$ ).

К сожалению, мы не сделали экстраполяцию РНП на 15-летнюю миссию для BC PANDA- $\mathrm{SiO}_{2}$, однако уже из сравнения $30 \mathrm{~min}$ релаксации этого ВС и ВC 1 на рис. 4 можно сделать выводы об ожидаемых РНП в космосе: при обоих температурах РНП в PAMDA-SiO будут не выше, чем в ВС 1, т.е. не выше, чем 0.27 и $1.1 \mathrm{~dB} / \mathrm{km}$ в конце 15-летней миссии, проведенной при $T=+25$ и $-60^{\circ} \mathrm{C}$ соответственно. Не исключено, что при $T=-60^{\circ} \mathrm{C}$ РНП будет даже ниже $1.1 \mathrm{~dB} / \mathrm{km}$.

\section{Заключение}

Пять ВС с сердцевиной из нелегированного $\mathrm{SiO}_{2}$, изготовленные при различных режимах MCVD-процесса и проявившие поэтому многократно различные РНП в процессе $\gamma$-облучения с высокой мощностью дозы $(\geq 1 \mathrm{~Gy} / \mathrm{s})$, показали тем не менее близкое РНП на длине волны $\lambda=1.55 \mu \mathrm{m}$ в процессе релаксации после $\gamma$-облучения до дозы $1 \mathrm{kGy}(\sim 1 \mathrm{~Gy} / \mathrm{s}):$ РНП всех ВС оставило всего $5.2 \pm 1.0 \mathrm{~dB} / \mathrm{km}$ при $T=-60^{\circ} \mathrm{C}$ уже через $30 \mathrm{~min}$ релаксации. Это означает, что содержание хлора в сетке стекла и ее деформации, создающие проблемы для применений ВС при большой мощности дозы, не будут играть заметной роли при применениях ВС в космосе.

РНП, измеренные в этих световодах методом оптической рефлектометрии при комнатной температуре через 173 дня после облучения, оказались в диапазоне $0.27-0.47 \mathrm{~dB} / \mathrm{km}$. Экстраполяция в рамках модели кинетики $n$-го порядка дала среднее значение РНП к концу 15-летней миссии, при комнатной температуре 
$\sim 0.3 \mathrm{~dB} / \mathrm{km}$ при разбросе между различными световодами $0.2-0.4 \mathrm{~dB} / \mathrm{km}$. Экстраполяция, сделанная для $T=-60^{\circ} \mathrm{C}$, дала значение РНП $\sim 1.1 \mathrm{~dB} / \mathrm{km}$ для той же дозы и продолжительности миссии, при этом точность экстраполяция в этом случае могла быть не столь высокой.

Таким образом, для космических применений ВС (в частности, для применений в волоконно-оптических гироскопах) нет необходимости проводить специальную оптимизацию технологических режимов изготовления преформ ВС с сердцевиной из нелегированного $\mathrm{SiO}_{2}$. Исключение германия из сердцевины будет достаточно для того, чтобы использовать ВС длиной, по меньшей мере, 4-5 km в условиях вариации температуры в космосе в пределах $-60^{\circ} \mathrm{C}$ при максимальной дозе $1 \mathrm{kGy}$ и длительности миссии 15 лет.

Экстраполяции РНП германосиликатных ВС - стандартного ВС для оптической связи SMF-28 и двулучепреломляющего ВС типа „ПАНДА“ - для случая 15-летней миссии, проведенной при $T=+25^{\circ} \mathrm{C}$ (доза $1 \mathrm{kGy}$ ) дали значения 4.3 и $17.5 \mathrm{~dB} / \mathrm{km}$ соответственно.

РНП двулучепреломляющего ВС типа „ПАНДА“ с сердцевиной из нелегированного $\mathrm{SiO}_{2}$ в процессе релаксации после $\gamma$-облучения до дозы $1 \mathrm{kGy}$ на $\lambda=1.55 \mu \mathrm{m}$ при $T=+25^{\circ} \mathrm{C}$ практически совпало с РНП в лучшем изотропном $\mathrm{BC}$, а при $T=-60^{\circ} \mathrm{C}$ оказались даже ниже. Это сравнение позволяет сделать вывод, что РНП к концу 15-летней миссии в данном двулучепреломляющем ВС будет не выше, чем в изотропных ВС. Таким образом, допустимо использование, по меньшей мере, 4-5 km данного двулучепреломляющего ВС в условиях вариации температуры в космосе в пределах $\pm 60^{\circ} \mathrm{C}$ при максимальной дозе $1 \mathrm{kGy}$ и длительности миссии 15 лет.

Работа поддержана Министерством образования и науки Российской Федерации. Проект № RFMEFI60417X0183.

\section{Список литературы}

[1] Friebele E.J., Gingerich M.E., Griscom D.L. // SPIE Proc. 1992. Vol. 1791. P. 177-188.

[2] Friebele E.J., Askinsa C.G., Millerb G.A., Peelea J.R., Wasserman L.R. // SPIE Proc. 2004. Vol. 5554. P. 120-131.

[3] Krabshuis G., Amezcua-Correa A., Gooijer F., Melin G., Kuyt G., Achten F.J., Geerings S.G.F., Bigot-Astruc M. // US Patent 9,405,062 В2 от 02.08.2016, приоритет от 26.04.2012.

[4] Lydtin H. // J. Lightw. Technol. 1986. Vol. 4. N 8. P. $1034-1038$.

[5] Курбатов А.М., Курбатов Р.А. // Письма в ЖТФ. 2010. T. 36. Вып. 17. С. 23-29. [Kurbatov A.M., Kurbatov R.A. // Technic. Phys. Lett. 2010. Vol. 36. N 9. P. 789-791. DOI: $10.1134 / \mathrm{S} 106378501009004 \mathrm{X}]$

[6] Курбатов А.М., Курбатов Р.А. // Патент РФ № 2472188. Приоритет от 02.04.2010. Зарегистрирован 10.01.2013.

[7] Tomashuk A.L., Salgansky M.Yu., Kashaykin P.F., Khopin V.F., Sultangulova A.I., Nishchev K.N., Borisovsky S.E., Guryanov A.N., Dianov E.M. // J. Lightw. Technol. 2014. Vol. 32. N 2. P. 213-219.
[8] Kashaykin P.F., Tomashuk A.L., Salgansky M.Yu., Abramov A.N., Nishchev K.N., Guryanov A.N., Dianov E.M. // J. Lightw. Technol. 2015. Vol. 33. N 9. P. 1788-1793.

[9] Girard S., Marcandella C., Alessi A., Boukenter A., Ouerdane Y., Richard N., Paillet Ph., Gaillardin M., Raine M. // IEEE Trans. Nucl. Sci. 2012. Vol. 59. N 6. P. 2894-2901.

[10] Griscom D.L. // J. Non-Cryst. Sol. 2006. Vol. 352. N 23. P. 2601-2617.

[11] Kashaykin P.F., Tomashuk A.L., Salgansky M.Yu., Abramov A.N., Iskhakova L.D., Lobanov N.S., Nishchev K.N., Guryanov A.N., Dianov E.M. // Proc. SPIE. 2015. Vol. 9507. P. $1-8$.

[12] Glavas X., Lembo L., Haraki W., Claxton Sh. // SPIE Proc. 1998. Vol. 3440. P. 120-130.

[13] Friebele E.J., Askins C.G., Shaw C.M., Gingerich M.E., Harrington C.C., Griscom D.L., Tsai T., Paek U., Schmidt W.H. // Appl. Optic. 1991. Vol. 30. N 15. P. 1944-1957.

[14] Lu Valle M.J., Friebele E.J., Dimarcello F.V., Miller G.A., Monberg E.M., Wasserman L.R., Wisk P.W., Yan M.F., Birtch E.M. // Proc. SPIE. 2006. Vol. 6193.

[15] McFadden J.D.O., Greenwell R., Hatch J., Barnes C., Pentrack D., Scott D. // Proc. SPIE. 1996. Vol. 2811. P. 77-86.

[16] Kashaykin P.F., Tomashuk A.L., Salgansky M.Yu., Guryanov A.N., Dianov E.M. // J. Appl. Phys. 2017. Vol. 121. N 21. P. 213104. 